\title{
A rare symplastic or bizarre leiomyoma of the scrotum: a case report and review of the literature Junaid Masood ${ }^{* 1}$, Stelios Voulgaris ${ }^{1}$, Peter Atkinson ${ }^{2}$ and Tom W Carr ${ }^{1}$
}

\author{
Address: ${ }^{1}$ Department of Urology, Southend University Hospital, Essex, UK and ${ }^{2}$ Department of Pathology, Southend University Hospital, Essex, \\ UK \\ Email: Junaid Masood* - junaido@aol.com; Stelios Voulgaris - bstelios@doctor.com; Peter Atkinson - peter.atkinson@southend.nhs.uk; \\ Tom W Carr - Tom.carr@southend.nhs.uk \\ * Corresponding author
}

Published: 9 December 2008

Cases Journal 2008, I:38I doi:10.1186/1757-1626-I-38|

This article is available from: http://www.casesjournal.com/content/I/I/38I

(C) 2008 Masood et al; licensee BioMed Central Ltd.

This is an Open Access article distributed under the terms of the Creative Commons Attribution License (http://creativecommons.org/licenses/by/2.0), which permits unrestricted use, distribution, and reproduction in any medium, provided the original work is properly cited.
Received: 13 November 2008

Accepted: 9 December 2008

\begin{abstract}
Background: We present a case of a symplastic or "bizarre" leiomyoma of the scrotum. Isolated cases of leiomyomas have been reported arising from the renal pelvis, bladder, spermatic cord, epididymis, prostate as well as the glans penis. However such mesenchymal lesions of the scrotum are very rare.

Case presentation: Macroscopically the tumour was a well-circumscribed grey-white lesion 8.5 $\mathrm{cm}$ in size. Because of its peculiar histological characteristics this tumour was assigned as a symplastic or bizarre leiomyoma of the scrotum.

Conclusion: We present this unusual tumour and highlight some important diagnostic and treatment pitfalls related to this rare tumour. This case demonstrates that leiomyomas should be considered in the differential diagnosis of scrotal tumours.
\end{abstract}

\section{Case presentation}

A 59-year old Caucasian man of average height and build presented with an 18-year history of a slowly enlarging, painless hard mass arising from the lower pole of his right scrotum (figure 1). There was no significant family or past medical history. On examination an 8 to 9 centimetre $(\mathrm{cm})$ pedunculated, firm but smooth, non-tender mass was found arising from the dependant part of his right scrotum. This mass was not adhered to deeper layers and was not transilluminable.

A scrotal ultrasound confirmed normal testes and cord structures but showed a bizarre solid mass with a heterogeneous disorganised pattern with poor vascularity suggesting a mesenchymal tumour arising from the scrotal wall. This mass was excised under a general anaesthetic.
The patient made a good recovery post-operatively. Macroscopically the tumour was a well-circumscribed greywhite lesion $8.5 \mathrm{~cm}$ in size. Because of its peculiar histological characteristics this tumour was assigned as a symplastic or bizarre leiomyoma of the scrotum.

\section{Discussion}

Conventional leiomyomas may originate from any anatomic location of smooth muscle in the genitourinary system[1]. Isolated cases of leiomyomas have been reported arising from the renal pelvis, bladder, spermatic cord, epididymis, prostate as well as the glans penis [1-4]. However mesenchymal lesions of the scrotum are rare lesions[5]. Leiomyomas are well known to be by far the commonest neoplasm arising from the uterus[6]. 


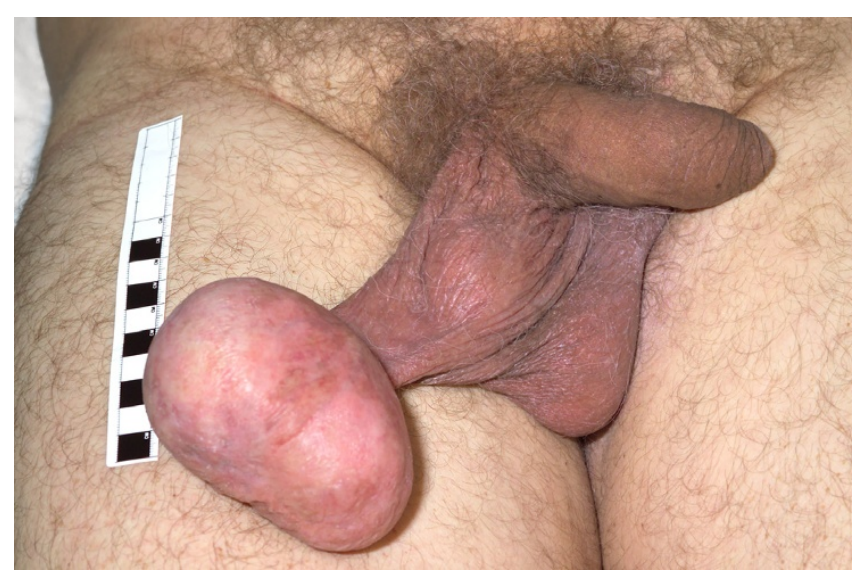

Figure I

Demonstrates the clinical appearance of this tumour arising from the dependant part of the right hemiscrotum.

Symplastic leiomyomas are rarely reported lesions in the medical literature [7-12] A medline search reveals less than 10 reports of symplastic or "bizarre" leiomyoma of the scrotum.

On gross sections these tumours appear white-grey and are well circumscribed and encapsulated. On high power images these neoplasms are characterised by interlacing bundles of spindle shaped muscle cells with pleomorphic nuclei and occasional nuclear inclusions (Figure 2). The muscular nature of these lesions can be demonstrated by positivity for Masson-trichrome staining[5]. There are no

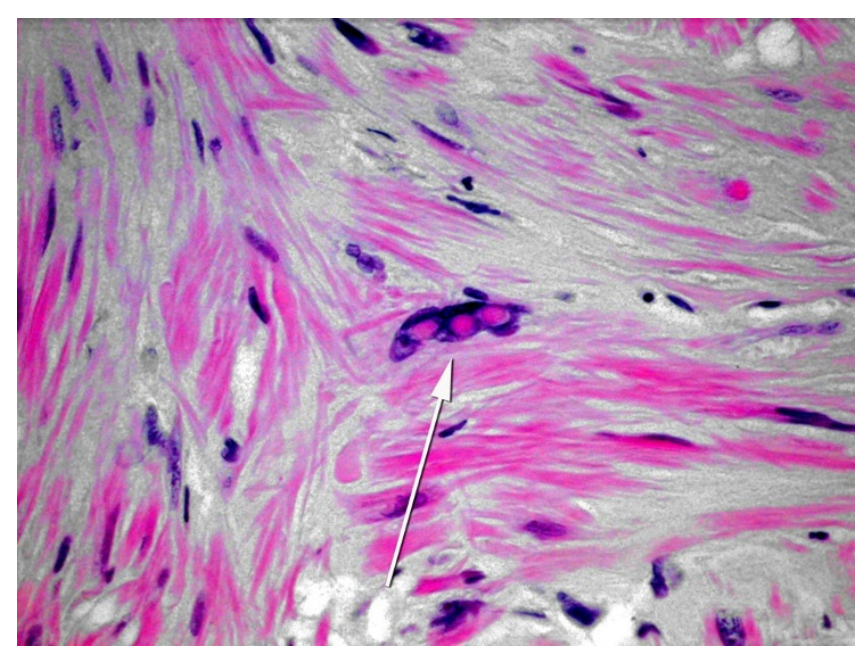

Figure 2

A histopathological slide demonstrating the characteristic interlacing bundles of spindle shaped muscle cells with pleomorphic nuclei and occasional nuclear inclusions found in symplastic leiomyomas. mitotic figures seen (Figure 2). Immunohistochemically, the tumour cells express vimentin, desmin, smooth muscle actin, and muscle specific actin, but not cytokeratin, neurofilament, or glial fibrillary acidic protein[11].

It is important to emphasize that despite their histological characteristics on presentation, compatible with malignancy, these tumours have a benign course not any different from conventional leiomyomas even when they are larger in size than those reported in the literature. In contrast to scrotal leiomyosarcomas, scrotal leiomyomas with bizarre nuclei are not hypercellular, and they lack mitotic activity[11].

Ultrasound scan appears to be the investigation of choice in the pre-operative assessment of these tumours $[7,9]$ and should ensure a proper surgical approach with simple excision of the tumour.

\section{Conclusion}

This case report highlights some important diagnostic and treatment issues related to this rare tumour. Histologically they behave differently to both conventional leiomyomas as well as leiomyosarcomas. Their behaviour is benign in nature although it is not clear if they can recur locally. Hence follow-up of these patients is advised. This report highlights the clinicopathological characteristics of the scrotal bizarre leiomyoma in order to increase our understanding, and avoid the possibility of erroneous diagnosis and treatment. It is very important to distinguish these bizarre or symplastic leiomyomas from leiomyosarcomas to avoid unnecessary treatment.

\section{Consent}

Written consent was obtained from the patient to publish this manuscript and accompanying images. A copy of this consent is available for review by the editor of this journal.

\section{Competing interests}

The authors declare that they have no competing interests.

\section{Authors' contributions}

$\mathrm{JM}$ and SV did the literature search and wrote the draft article. PA was responsible for the histology slide and histological input. TWC revised the article for intellectual content.

\section{References}

I. Belis JA, et al.: Genitourinary leiomyomas. Urology 1979, 13(4):424-9.

2. Borri A, et al.: Bizarre leiomyoma of the epididymis. A case report. Minerva Urol Nefrol 2000, 52(1):29-31.

3. Rosen $Y$, et al.: Atypical leiomyoma of prostate. Urology 1980 , I5(2): I83-5.

4. Redman JF, et al.: Leiomyoma of the glans penis in a child. J Urol 2000, 164(3 Pt I):791. 
5. De Rosa G, et al.: Symplastic leiomyoma of the scrotum. A case report. Pathologica 1996, 88(I):55-7.

6. Robboy SJ, et al.: Pathology and pathophysiology of uterine smooth-muscle tumours. Environ Health Perspect 2000, 108(Suppl 5):779-84.

7. Habuchi T, et al.: Leiomyoma of the scrotum: a case report and sonographic findings. Hinyokika Kiyo 1990, 36(8):959-62.

8. Kim NR, et al:: Bizarre leiomyoma of the scrotum. J Korean Med Sci 2003, 18(3):452-4.

9. Cabello Benavente R, et al:: Giant bizarre scrotal leiomyoma. Arch Esp Urol 2004, 57(8):847-5I.

10. Sevilla Chica F, et al: Atypical or bizarre leiomyoma of the scrotum. Report of one case and bibliographic review. Arch Esp Urol 2004, 57(4):428-3I.

II. Slone S, et al: Scrotal leiomyomas with bizarre nuclei: a report of three cases. Mod Pathol 1998, I I (3):282-7.

12. Erkilic S, et al.: Primary leiomyoma of the thyroid gland. J Laryngol Otol 2003, II 7(10):832-4.

Publish with Biomed Central and every scientist can read your work free of charge

"BioMed Central will be the most significant development for disseminating the results of biomedical research in our lifetime. "

Sir Paul Nurse, Cancer Research UK

Your research papers will be:

- available free of charge to the entire biomedical community

- peer reviewed and published immediately upon acceptance

- cited in PubMed and archived on PubMed Central

- yours - you keep the copyright

Submit your manuscript here:

http://www.biomedcentral.com/info/publishing_adv.asp 